\title{
Lipid oxidation kinetics of ozone-processed shrimp during iced storage using peroxide value measurements
}

Charles Odilichukwu R. Okpala, Gioacchino Bono, Michele Luca Geraci, Giacomo Sardo, Sergio Vitale, Carl J. Schaschke

This is the accepted manuscript () 2016, Elsevier Licensed under the Creative Commons AttributionNonCommercial-NoDerivatives 4.0 International: http://creativecommons.org/licenses/by-nc-nd/4.0/

\section{(c) $(1) \Theta$}

The published article is available from doi: http://dx.doi.org/10.1016/j.fbio.2016.07.005 


\section{Author's Accepted Manuscript}

Lipid oxidation kinetics of ozone-processed shrimp during iced storage using peroxide value measurements

Charles Odilichukwu R. Okpala, Gioacchino Bono, Michele Luca Geraci, Giacomo Sardo, Sergio Vitale, Carl J. Schaschke

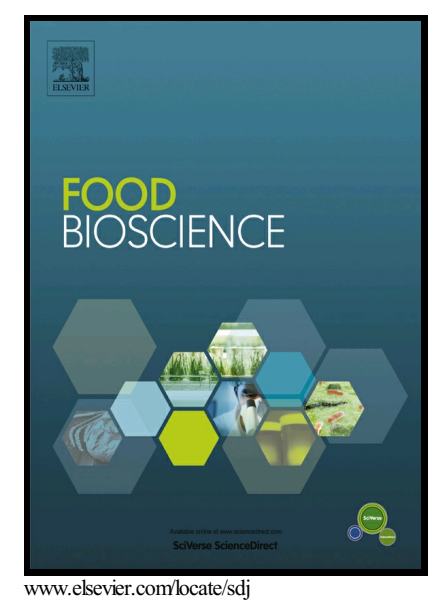

PII: $\quad$ S2212-4292(16)30051-7

DOI: $\quad$ http://dx.doi.org/10.1016/j.fbio.2016.07.005

Reference: $\quad$ FBIO167

To appear in: Food Bioscience

Received date: 23 February 2016

Revised date: 12 July 2016

Accepted date: 13 July 2016

Cite this article as: Charles Odilichukwu R. Okpala, Gioacchino Bono, Michel Luca Geraci, Giacomo Sardo, Sergio Vitale and Carl J. Schaschke, Lipis oxidation kinetics of ozone-processed shrimp during iced storage using peroxid value measurements, Food

Bioscienct

http://dx.doi.org/10.1016/j.fbio.2016.07.005

This is a PDF file of an unedited manuscript that has been accepted fo publication. As a service to our customers we are providing this early version o the manuscript. The manuscript will undergo copyediting, typesetting, an review of the resulting galley proof before it is published in its final citable form Please note that during the production process errors may be discovered whic could affect the content, and all legal disclaimers that apply to the journal pertain 
Lipid oxidation kinetics of OZOne-processed shrimp during iced storage using peroxide value measurements

Charles Odilichukwu R. Okpala ${ }^{a, b^{*}}$, Gioacchino Bono ${ }^{b}$, Michele Luca Geraci ${ }^{b 1}$, Giacomo Sardo ${ }^{\mathrm{b} 1}$, Sergio Vitale ${ }^{\mathrm{b}}$, Carl J. Schaschke ${ }^{\mathrm{c}}$

${ }^{a}$ School of Science, Monash University Sunway Campus, 46150 Bandar Sunway, Selangor D.E., Malaysia

'Istituto per l' Ambiente Marino Costiero, Consiglio Nazionale delle Ricerche (IAMC-CNR), 91026 Mazara del Vallo, Italy.

'School of Science, Engineering and Technology, Abertay University, Dundee DD1 1HG, United Kingdom.

'Correspondence. Istituto per I' Ambiente Marino Costiero, Consiglio Nazionale delle Ricerche (IAMC-CNR), Mazara del Vallo, Italy. Tel.: +393711206926; fax.: +3909239066. charlesokpala@gmail.com

Abstract

In this research, in situ generated ozone exposure/wash cycles of 1, 3, and 5 min applied to shrimp samples either before (BIS) or during iced storage (DIS) has been used to study the lipid oxidation kinetics using the peroxide values (PV). The induction period (IP) as well as $\mathrm{PV}$ at end of the IP $\left(\mathrm{PV}_{\mathbb{I P}}\right)$ have been obtained. The rate constants $(\mathrm{k})$ as well as half-lives $\left(t_{1 / 2}\right)$ of hydroperoxides formation for different oxidation stages were calculated. The results showed that both IP and $\mathrm{PV}_{\mathrm{IP}}$ were lower with BIS (IP between $4.35 \pm 0.09$ and $5.08 \pm 0.23$ days; $\mathrm{PV}_{\mathrm{IP}}$ between $2.92 \pm 0.06$ and $3.40 \pm 0.18 \mathrm{mEq} \mathrm{kg}{ }^{-1}$ ) compared with DIS (IP between $5.92 \pm 0.12$ and $6.14 \pm 0.09$ days; $\mathrm{PV}_{\mathrm{IP}}$ between $4.49 \pm 0.17$

1 These authors participated equally in this study. 
and $4.56 \pm 0.10 \mathrm{mEq} \mathrm{kg}^{-1}$ ). The $\mathrm{k}$ value for DIS seemed to be the greater compared to BIS. In addition, whilst decreases and increases in $t_{1 / 2}$ were found at propagation, respectively, for BIS and DIS, decreases and increases were only found at the induction of oxidation stage(s) for BIS. Further, the PV of ozone-processed samples would fit first order lipid oxidation kinetics independent of duration of ozone exposures. For the first time, PV measurements and fundamental kinetic principles have been used to describe how increasing ozone exposures positively affects the different oxidation stages responsible for the formation of hydroperoxides in ozone-processed shrimp.

\section{Abbreviations}

PUFA, Polyunsaturated fatty acids; PV, Peroxide value; IP, Induction period; BIS, Before iced storage; DIS, During iced storage; GRAS, Generally Recognized As Safe Key words: Ozone treatment; Litopenaeus vannamei, Lipid autoxidation, Hydroperoxide formation, Oxidation rate.

\section{Introduction}

Fish and fish products are rich sources of long chain polyunsaturated fats (PUFA), particularly omega-3 fatty acids (Okpala, 2015 and 2016; Sae-leaw \& Benjakul, 2014; Robinson \& Mazurak, 2013), which make them highly susceptible to oxidative degradation particularly during processing. Inevitably, the progress of lipid oxidation facilitates the undesirable losses in fish product quality (Bono et al., in-press; Campos et al., 2006; Medina-Meza et al., 2014; Okpala et al., 2014).

As a degradation process at the double bond in unsaturated fatty acids, lipid oxidation is among major deteriorative reactions that limits both acceptability and quality of (sea)food products (Bono et al., in-press; Colakoglu, 2007; Okpala, 2016; Okpala et al., in-press). The oxidation in particular proceeds through a free radical chain mechanism, the so-called autoxidation, which generally involves three distinct stages of 
ACCEPTED MANUSCRIPT

initiation, propagation and termination, as simplified in Fig. 1. This can be impacted by the natural enzyme systems, metal catalysis, solar or thermal energy, and/or non-radical and radical oxygen species $\left(\mathrm{O}_{2}, \mathrm{O}_{3}, \mathrm{H}_{2} \mathrm{O}_{2}, \mathrm{ROOH}\right.$, etc.). During the initiation stage, there is the abstraction of hydrogen radicals $\left(\mathrm{H}^{*}\right)$ that yield free lipid radicals $\left(\mathrm{R}^{\star}\right)$, whereas during the propagation stage there is the combination of oxygen with free lipid radicals to form peroxyl radicals $\left(\mathrm{RO}_{2}{ }^{*}\right)$, which go on to produce lipid hydroperoxides $\left(\mathrm{RO}_{2} \mathrm{H}\right)$ and a radical $\left(R^{*}\right)$. Further, the subsequent reactions eventually lead to termination stage that brings about non-radical products (Colakoglu, 2007; Medina-Meza et al., 2014; Okpala, 2016; Schaich, 2005; Shahidi \& Zhong, 2010; Shim \& Lee, 2011). In reality however, different intermediates and end products can be expected during the initiation and propagation stages (Gardner, 1989; Porter \& Wujek, 1987; Schaich, 2005). Following a literature search, it was found that the majority of previously published lipid oxidation studies have largely focused on one single aspect of reactions such as the kinetics of oxygen uptake, analyses of specific catalysts, and antioxidant effects on oxidation. The mechanisms for oxidation have been interpreted in the (above-highlighted) context(s) of these single aspects.

The kinetic evaluation of reactions for either the appearance of hydroperoxides or consumption of oxygen heretofore has been used to help understand lipid oxidation mechanisms (Colakoglu, 2007; Schaich, 2005). Moreover, whereas increases in concentration of hydroperoxide is associative of fatty acids amply present in crustacean products' flesh/muscle that inevitably undergo oxidation with storage (Bono et al., inpress; Okpala et al., 2014), the use of peroxide value (PV) measurements already experimentally ascertained to correspond with the rate of oxygen consumption/uptake makes it (i.e., PV) among the useful parameters that can be employed in the kinetic evaluation of lipid autoxidation (Colakoglu, 2007; Kamal-Eldin, 2003). And along with 
ACCEPTED MANUSCRIPT

such knowledge about the mechanisms involved in the formation of hydroperoxides(s), more effective control measures can therefore be developed to help prevent (additional) oxidation in bio-food systems (Kamal-Eldin, 2003). At the initial stage of lipid oxidation, a sudden rise in PV has been used to help define the induction period (IP), the latter also quantifiable by other measurement approaches such as the use of Rancimat methods, electron spin resonance (ESR) as well as exothermic thermograms using differential scanning calorimetry (DSC) (Farhoosh \& Hoiseni-Yazdi, 2013; Shim \& Lee, 2011). Because lipid oxidation is among the quality features of postharvest crustacea such as shrimp that has been reported to show considerable increases particularly at the later stages of iced storage (Bono et al., in-press; Okpala et al., 2014; Okpala, 2014, 2015 and 2016; Okpala et al., in-press), to attain better/improved understanding about the IP may therefore be potentially valuable for determining the effective shelf life (Farhoosh, 2007; Farhoosh \& Hoiseni-Yazdi, 2013; Shim \& Lee, 2011) under different processing and storage conditions.

Among the different innovative food process methods employed today to extend the shelf life of (fresh) food products, the use of ozone has been a "Generally Recognized as Safe (GRAS)" process for over three decades and has also been indicated promising for processing seafood such as crustacea. However, through the quantification of (either primary or secondary) lipid oxidation parameters such as peroxide value, $p$-anisidine value ( $p-A n V)$ as well as thiobarbituric acid (TBA), ozone treatments have been shown to slow down the lipid autoxidation in seafood products (Campos et al., 2006; O'Donnell et al., 2012; Okpala, 2014, 2015 and 2016; Okpala, et al., in-press). On the other hand and regrettably, the use of iced storage alone as is commonly employed within the fishery supply chain cannot completely prevent the postharvest progress in lipid breakdown/damage (Okpala et al., in-press; Sae-leaw \& Benjakul, 2014). However, no publication reporting on the lipid oxidation kinetics of ozone-processed crustacea such as 
shrimp during cold/iced storage has been found. Therefore to supplement the current literature, the specific objective of this study was to use peroxide value (PV) measurements to determine the lipid oxidation kinetics of ozone-processed shrimp during refrigerated storage $\left(\sim 4^{\circ} \mathrm{C}\right)$. Notably, both the induction periods (IP) and PV during the IP $\left(P V_{\mathbb{I P}}\right)$ has been determined.

\section{Materials and methods}

2.1. Chemicals

Chloroform, potassium iodide, as well as sodium thiosulphate were from Friedemann Schmidt Chemicals' brand obtained from ChemoLab (Kuala Lumpur, Malaysia). Glacial acetic acid has been procured from Sigma (St. Louis, MO, USA). All chemicals employed for this study were of reagent grade.

2.2. Sample collection

The Litopenaeus spp. shrimp (10 kg; length $=\sim 10-13 \mathrm{~cm}$; weight $=\sim 9-11 \mathrm{~g})$ were freshly harvested from a local farm in Selangor, Malaysia and prepared as previously described (Okpala et al., 2014; Okpala, 2014 and 2015; Okpala et al., in-press) consistent with Malaysian Standard MS 1500: 2009. Samples were promptly washed and packaged in clean polyethylene bags. The packaged samples were stored in Styrofoam boxes using an ice/shrimp ratio of $1: 2(\mathrm{w} / \mathrm{w})$ and transported to the laboratory in $\sim 2 \mathrm{~h}$ and upon arrival, kept in walk-in cold room $\left(\sim 4^{\circ} \mathrm{C}\right)$ until required.

\subsection{Ozone treatment of sample}

Shrimp samples were ozone-processed using an on-site ozone generating facility ('The O3 Fresh', Model SXQ8-BA-W, Ovoproducts, Leicestershire, UK), which has been manufactured with an ozone concentration discharge of $100 \mathrm{mg} / \mathrm{h}$ into water, a wash and spin capacity of $4 \mathrm{~L}$, three ozone exposure levels/wash cycles of 1,3 , and $5 \mathrm{~min}$, and maximum loading capacity of $1.5 \mathrm{~kg}$. The ozone exposure/wash cycle times were used to 
define the ozone treatments.

\section{ACCEPTED MANUSCRIPT}

\subsection{Storage conditions}

Specific to this study, two different systems were tested, namely: increasing ozone exposures before (BIS) and during iced storage (DIS). Both systems used storage periods that lasted up to 11 days. Prior to ozone treatment, the removable basket as well as ozonation space has been sterilized, which involved a 60 s run of ozone facility using tap water only at beginning and end of ozone processing of batch/lot, in between which the ozone processing of samples has been performed. For the BIS scenario, ozone treatment was applied to fresh samples (day 0) and thereafter kept in ice during which analysis (refer to Section 2.4) using different samples were performed specifically on storage days $1,2,3,5,8$ and 11 . For the DIS scenario, ozone treatment was applied to the untreated ice-stored samples specifically on the same above-mentioned (analysis) days for BIS and immediately thereafter, analysis (refer to Section 2.4) on different samples. When the ozone equipment had completed any given wash cycle, water automatically drained out within $\sim 2 \min$. All processed samples $(\sim 200 \mathrm{~g})$ were (re)packaged using sterile polethylene bags (Reynolds® Zipper, Alcoa Products Inc., Pittsburgh, PA- USA) and imbedded in ice-containing polystyrene boxes of shrimp/ice ratio of 1:2 (w/w), and either kept in a walk-in cold room $\left(\sim 4{ }^{\circ} \mathrm{C}\right)$ until required for analysis. To maintain the sample/ice ratio for both systems, clumped ice in the polystyrene boxes were periodically removed and replaced every $24-48 \mathrm{~h}$.

\subsection{Peroxide value (PV) measurements}

Several authors (Farhoosh \& Hoiseni-Yazdi, 2013; Kamal-Eldin, 2003; Kirk and Sawyer, 1991; Okpala, 2014, 2015 and 2016; Okpala et al., in-press; Schaich, 2005; Shahidi \& Zhong, 2010) have reported on the use of PV to quantify the primary lipid oxidation products to explain the extent/degree of formation of hydroperoxides in food systems. The present study used the method of Kirk and Sawyer (1991) with slight 
ACCEPTED MANUSCRIPT

modifications. PV measurements were done four times using different ozone-processed shrimp samples. This involved an $\sim 4 \mathrm{~g}$ blended (Waring ${ }^{\circledR}$ Blender, Shelton $\mathrm{CT}$, USA) sample $(M)$ mixed with chloroform $(10 \mathrm{~mL})$ and glacial acetic acid $(15 \mathrm{~mL})$, which was then filtered using Qualitative Circles filter paper (125 mm diameter) (GE Healthcare, Buckinghamshire, UK). Following this, the filtrate was shaken vigorously for approximately $30 \mathrm{~s}$ while $1 \mathrm{~mL}$ of fresh saturated aqueous potassium iodide (KI) solution was added dropwise and the sample left in the dark for $5 \mathrm{~min}$. An equivalent volume of distilled water was added to release the iodine followed by titration with $0.01 \mathrm{M}(\mathrm{T})$ of sodium thiosulphate solution $\left(\mathrm{V}_{1}\right)$ along with a blank $\left(\mathrm{V}_{0}\right)$ with no processed shrimp sample. The PV was expressed in milli-equivalents of active oxygen per one kilogram ( $\mathrm{mEq}$ active $\mathrm{O}_{2} / \mathrm{kg}$ ) of processed shrimp sample, as determined using Eq. 1:

$$
P V=\frac{\left(V_{1}-V_{o}\right) T \times 10^{3}}{M}
$$

where the variables ' $V_{1}$ ' represent the volume of sodium thiosulphate solution $(\mathrm{mL})$, ' $\mathrm{V}_{0}$ ' represent the volume of the blank $(\mathrm{mL})$, ' $M$ ' represent the mass of sample and ' $T$ ' represent the molarity of sodium thiosulphate solution.

2.6. Induction period (IP) measurements

The evolution of hydroperoxides during iced storage period has provided kinetic curves that comprised of two stages, namely the induction as well as propagation phases. Consistent with the approach previously used by Farhoosh and Hoseini-Yazdi (2013) as well as Shim and Lee (2011), the IP has been used to define the point where there is a sudden rise in PV of ozone-processed shrimp during iced storage of this current study. To quantify the IP specifically, the two linear regression lines representing induction and propagation phases were fitted based on the actual PV values, depicted in Fig. 2. The intersection point of the two regression lines that defined the end of the IP has been identified in terms of time $\left(\mathrm{IP}_{\mathrm{PV}}\right.$ and $\left.\mathrm{PV}_{\mathrm{IP}}\right)$. 


\section{ACCEPTED MANUSCRIPT}

\subsection{Lipid oxidation kinetics}

Based on previous studies (Farhoosh \& Hoseini-Yazdi, 2013; Shim \& Lee, 2011), the kinetics before and after IP of ozone-processed shrimp evaluated for the induction and propagation periods. The oxidation kinetics has previously been shown such that Eqs (1) and (2) are functions where the reaction rates do not depend on the oxidizing substrate concentration and therefore, can be modeled as pseudo-zero order reactions (Farhoosh \& Hoseini-Yazdi, 2013; Shim \& Lee, 2011) (Eq. 2):

$P V_{I P}=P V_{0}+k_{1}\left(I P_{P V}\right)$

Then using the end of IP and keeping its $\mathrm{PV}_{\mathbb{I P}}$ constant, the peroxide value at any time after induction is (Eq. 3):

$P V=P V_{I P}+k_{2}(t-I P)=k_{1} I P+k_{2}(t-I P)$

where $\mathrm{PV}_{0}$ and $\mathrm{PV}$ are the concentrations of hydroperoxides at the beginning and after iced storage time(s) $t$, whereas $k_{1}$ and $k_{2}$ give the oxidation rate constants for the induction and propagation periods from the slope of fitted/regression lines, respectively (Fig. 2). Given that the initial $P V$ is minimal, the $P V_{0}$ in Eq. 3 has been neglected (Farhoosh \& Hoseini-Yazdi, 2013; Shim \& Lee, 2011).

The half-lives $\left(t_{1 / 2}\right)$, which specifically for this current study represented the time for half of the lipids present to be converted to hydroperoxides, was also determined. The oxygen-involved induction and propagation stages of lipid oxidation during iced storage of ozone-processed samples may well be described using first order kinetics as previously reported by Colakoglu (2007) using Eq. 4:

$$
-\frac{d O_{2}}{d t}=k t
$$

Integrating between the initial and final oxygen concentrations gives Eq. 5:

$\ln O_{2(t)}=\ln O_{2(0)}-k t$ 
ACCEPTED MANUSCRIPT

where $\mathrm{k}$ is the first order oxidation reaction constant that can be identified with $\mathrm{k}_{1}$ and $\mathrm{k}_{2}$, respectively, of the induction and propagation periods. Thus, the half-life would be expressed in Eq. 6 given below as:

$t_{1 / 2}=\frac{\ln 2}{k}$

\subsection{Statistical analysis}

Using Eq. 2 and 3, the rate constants have been determined. In most cases, the resultant data are reported as mean values \pm standard error (of the means). To establish any statistically significant differences between the resultant data arising from BIS and DIS technological situations, the Student t-test was applied at the probability level of $\mathrm{p}<0.05$. Minitab Express ${ }^{\mathrm{TM}}$ software (version 1.3.0 for Mac, Minitab Ltd., Coventry, UK) was used to do the statistical analysis.

\section{Results and discussion}

The processes that underpin lipid oxidation of foods in that there may appear complicated continue to adhere to fundamental chemical reaction mechanisms previously demonstrated by Shahidi and Zhong (2010), depicted herein and succinctly in the Fig. 1 . Nonetheless, to reconcile oxidation kinetics and its corresponding/emergent equations have often come with difficulties even in simple systems, which have largely been based on assumptions (Pilpel \& Hunter, 1970; Schaich, 2005; Shahidi \& Zhong, 2010) and as such would underline the derivation of resultant kinetic equations as well as nature of oxidizing compound. Amid the possible sources of discrepancies in lipid oxidation mechanism explorations, some of these assumptions still complement the kinetic measurements (Schaich, 2005). As already displayed herein in Fig. 2, the gradients of induction and propagation stages respectively have been used to determine the oxidation rate constants $k_{1}$ and $k_{2}$ (Farhoosh \& Hoseini-Yazdi, 2013; Shim \& Lee, 2011). And 
consequently, the PV of ozone-processed shrimp at both before (BIS) and during iced storage (DIS) situations appears to indicate first order lipid oxidation kinetics independent of the duration of exposure of the ozone discharged. In addition, the rate constant value at the DIS seems to be the greater compared to the BIS situation, as showed in Table 1. Earlier, Schaich (2005) postulated that both increase in reaction rate together with the fit of kinetic data within the lipid oxidation mechanism might well improve as the dissociation $\mathrm{C}-\mathrm{H}$ bond energies decrease with increase in chain length.

With increasing ozone exposures, both IP and $\mathrm{PV}_{\mathbb{I P}}$ showed lower values for BIS compared to DIS systems of ozone-treated shrimp, as shown in Table 2. In addition, the range of $\mathrm{IP}$ and $\mathrm{PV}_{\mathbb{I P}}$ of ozone-processed shrimp showed some tendencies to extend/widen more for BIS (IP between $4.35 \pm 0.09$ and $5.08 \pm 0.23$ days; $\mathrm{PV}_{\mathrm{IP}}$ between $2.92 \pm 0.06$ and $3.40 \pm 0.18 \mathrm{mEq} \mathrm{kg}^{-1}$ ) compared with the DIS (IP between $5.92 \pm 0.12$ and 6.14 \pm 0.09 days; $\mathrm{PV}_{\mathrm{IP}}$ between $4.49 \pm 0.17$ and $4.56 \pm 0.10 \mathrm{mEq} \mathrm{kg}{ }^{-1}$ ) systems. In particular, whilst the IP and $\mathrm{PV}_{\mathrm{IP}}$ increased between ozone exposures of 1-3 min, there appeared to be a slight decrease at 5 min that might suggest an earlier/initial decrease in the formation of hydroperoxides between ozone exposures of 1 - 3 min, which could subsequently increase at $5 \mathrm{~min}$ and more for BIS compared to DIS. Therefore, the addition of antioxidant would be considered as an effective way to slow the length of the induction period (IP) (Kamal-Eldin, 2003). The PV of ozone-processed shrimp decreased and increased with increasing ozone exposures and iced storage (Okpala et al., inpress). Table 3 also shows that the respective IP were positively correlated with PV for BIS and DIS $(P<0.05)$ with an explained variance that ranged between 70 and $~ 94 \%$. Given that the lipid oxidation kinetics would mostly reflect activity after the IP, the beginning of a quality loss for lipid-related products might occur shortly after the IP. Furthermore, both the formation rate and accumulation of primary oxidation products 
ACCEPTED MANUSCRIPT

could increase with the degree of unsaturation of fatty acids particularly at the end of the IP (Farhoosh \& Hoseini-Yazdi, 2013; Shim \& Lee, 2011). But with regards to the degree of unsaturation of fatty acids, the increasing ozone exposures between 1 and 3 min might on the contrary be inhibiting such increases, which tends to suggest an earlier/initial decrease in the rate of formation of the primary oxidation products. Moreover, the PUFA present in crustacea such as shrimp (Bono et al., in-press; Okpala et al., 2014; Okpala, 2016; Okpala et al., in-press) might also be inhibiting the IP initially. Equally, it is feasible that within the lipid system, both the concentration and structure of antioxidants might directly affecti the oxidation kinetics during the induction/initial stages (Kamal-Eldin, 2003). Drawing on the above arguments therefore shows some positive correlation with increases in PV during the IP of lipid-related food products.

Given that the effectiveness of ozone depends on its decomposition rate as it readily degrades, its half-life $\left(t_{1 / 2}\right)$ has been well established that it remains longer in the gaseous compared to the aqueous state (O'Donnell et al., 2012). Therefore, to examine the $t_{1 / 2}$ for the formation of hydroperoxides of ozone-processed shrimp during iced storage was considered essential as both lipid oxidation mechanisms and ozone processes interact with oxygen. Notably, increasing ozone exposures can be seen to produce somewhat limited changes in $t_{1 / 2}$ for DIS compared with BIS, as showed in Table 4. Specifically, some increase(s) and thereafter decrease(s) in $t_{1 / 2}$ were seen with both DIS and BIS at the oxidation propagation stage. On the other hand, some decrease(s) and thereafter increase(s) in $t_{1 / 2}$ were seen only with BIS during the induction/initial oxidation stage(s). And regardless of the ozone process regimes herein, the $t_{1 / 2}$ of induction/initial and oxidation propagation stages, respectively, ranged between $25.7-44.9$ and $11.0-$ 19.4 h. Fig. 3 clearly showed that both oxidation stages would correlate positively $(P<0.0001, F$-change $=39.16, R$-sq $(\operatorname{adj})=62.4 \%)$. Therefore, connecting the above $t_{1 / 2}$ 
ACCEPTED MANUSCRIPT

findings with the oxidation rate constants, it is plausible that the addition of antioxidant to impact on the IP (Kamal-Eldin, 2003) may well suggest that the increasing ozone exposures of this study might beneficial influence the $t_{1 / 2}$ of formation of hydroperoxides at both the induction/ initial and propagation stages of the ozone-processed shrimp.

\section{Concluding remarks}

For the first time, PV measurements have been used to do lipid oxidation kinetics of ozone-processed shrimp during iced storage as affected by increasing ozone exposures. It appears that the PV of ozone-processed shrimp with both BIS and DIS treatments fit first order lipid oxidation kinetics independent of duration of ozone exposures. Thus, the likely behavior of IP, $\mathrm{PV}_{\mathbb{I P}}$, as well as the half-life of ozoneprocessed shrimp during iced storage as affected by increasing ozone exposures has been determined, through the help of fundamental kinetic principles. Indeed, this study contributes to the understanding of lipid oxidation kinetics of ozone-processed seafood such as crustacea. However, to determine from the current study of lipid oxidation kinetics after increasing ozone exposures whether BIS or DIS would be favored to improve product quality appears inconclusive. Thus, the direction of future investigations concerning the lipid oxidation kinetics of ozone-processed crustacea should consider incorporating different process and storage temperatures to better understand the lipid oxidation mechanism(s) and associated activation energies $\left(E_{a}\right)$ toward shelf life prediction. The data provided by this study, although isothermally limited to temperature of $\sim 4{ }^{\circ} \mathrm{C}$, provides some insights relevant to lipid oxidation research particularly with respect to the kinetic evaluation of ozone-processed seafood.

Conflict of Interest Statement

Authors have declared that there is no conflict of interest associated with this study. 
Acknowledgment

\section{ACCEPTED MANUSCRIPT}

Research funding to the corresponding author by Monash University Sunway Campus Malaysia is hereby acknowledged. Financial support from the Italian Ministero dell'Istruzione, dell'Università e della Ricerca, PON R\&C 2007-2013 (project PESCATEC) and PNR 2011-2013 (project RITMARE) is also acknowledged. Dr. Joe M. Regenstein, Professor Emeritus of Food Science at Cornell University (Ithaca, NY-USA) as well as other anonymous reviewers (of the journal) are thanked for their great efforts in improving the quality of this paper.

\section{References}

Bono, G., Okpala, C.O.R., Badalucco, C.V., Milisenda, G., \& Vitale, S. (In-press). Influence of freezing and oxygen-free packaging methods on lipid oxidation and other flesh quality parameters of Norway lobster (Nephrops norvegicus). European Journal of Lipid Science and Technology (doi: 10.1002/ejlt.201600035).

Campos, C.A., Losada, V., Rodriguez, O., Aubourg, S.A., \& Velazquez, J.B. (2006). Evaluation of an ozone-slurry ice combined refrigeration system for the storage of farmed turbot (Psetta maxima). Food Chemistry 97, 223-230.

Colakoglu, A.S. (2007). Oxidation kinetics of soybean oil in the presence of monoolein, stearic acid and iron. Food Chemistry 101(2), 724-728.

Farhoosh, R. (2007). Shelf-life prediction of edible fats and oils using Rancimat. Lipid Technology 19(10), 232-234.

Farhoosh, R., \& Hoseini-Yazdi, S-Z. (2013). Shelf-life prediction of olive oils using empirical models developed at low and high temperatures. Food Chemistry 141(1), 557-565.

Gardner, H.W. (1989). Oxygen radical chemistry of polyunsaturated fatty acids. Free Radical Biology and Medicine 7(1), 65-86.

Kamal-Eldin, A. (Ed.) (2003). Lipid oxidation pathways. Champaign, Illinois, USA: AOCS Press, pp. 323, (ISBN 978-1893997431).

Kirk, R.S., \& Sawyer, R. (1991). Pearson's composition and analysis of foods ( $9^{\text {th }}$ Edition), Essex, UK: Longman Group UK Limited, pp. 708 (ISBN 978-0582409101). 
Medina-Meza, I.G., Barnaba, C., \& Barbosa-Cánovas, G.V. (2014). Effects of high pressure processing on lipid oxidation: A review. Innovative Food Science and Emerging Technologies 22, 1-10.

O'Donnell, C., Tiwari, B.K., Cullen, P.J., \& Rice, R.G. (Eds) (2012). Ozone in food processing, Chichester, UK: Wiley-Blackwell, pp. 312, (ISBN 978-1444334425).

Okpala, C.O.R. (2014). Investigation of quality attributes of ice-stored Pacific white shrimp (Litopenaeus vannamei) as affected by sequential minimal ozone treatment. LWT-Food Science and Technology 57, 538-547.

Okpala, C.O.R. (2015). Quality evaluation and shelf life of minimal ozone-treated Pacific white shrimp (Litopenaeus vannamei) stored on ice. Journal für Verbraucherschutz und Lebensmittelsicherheit 10(1), 49-57.

Okpala, C.O.R. (2016). Lipid autoxidation in ozone-processed crustacea under cold storage: A treatise. Lipid Technology 28 (5-6), 93-95.

Okpala, C.O.R., Bono, G., Cannizzarro, L., \& Jereb, P. (In-press). Changes in lipid oxidation and related flesh qualities of white shrimp (Litopenaeus vannamei) during iced storage: Effects on the use of increasing ozone exposures. European Journal of Lipid Science and Technology (doi:10.1002/ejlt.201500347).

Okpala, C. O. R., Choo, W. S., \& Dykes, G. A. (2014). Quality and shelf-life assessment of Pacific white shrimp (Litopenaeus vannamei) freshly harvested and stored on ice. LWT-Food Science and Technology 55 (1), 110-116.

Pilpel, N., \& Hunter, B.F.J. (1970). The oxidation and decomposition of monomolecular films of stearic acid under ultraviolet irradiation. Journal of Colloid and Interface Science 33(4), 615-622.

Porter, N.A., \& Wujek, D.G. (1987). Autoxidation of polyunsaturated fatty acids, an expanded mechanistic study. Journal of the American Chemical Society 106(9), 2626-2629.

Robinson, L.E., \& Mazurak, V.C. (2013). N-3 polyunsaturated fatty acids: relationship to inflammation in healthy adults and adults exhibiting features of metabolic syndrome. Lipids, 48(4), 319-332.

Sae-leaw, T., \& Benjakul, S. (2014). Fatty acid composition, lipid oxidation and fishy odour development in seabass (Lates calcarifer) skin during iced storage. European Journal of Lipid Science and Technology 116, 885-894. 
Schaich, K.M. (2005). Lipid Oxidation: Theoretical Aspects. In: Bailey's Industrial Oil and Fat Products (6 $6^{\text {th }}$ Edition), Vol. 1, New Jersey, USA: Wiley and Blackwell pp. 269355.

Shahidi, F., \& Zhong, Y. (2010). Lipid oxidation and improving the oxidative stability. Chemical Society Reviews 39, 4067-4079.

Shim, S.D., \& Lee, S. J. (2011). Shelf-life prediction of perilla oil by considering the induction period of lipid oxidation. European Journal of Lipid Science and Technology 113, 904-909.

Fig. 1: A simplified scheme for the lipid autoxidation mechanism. Figure reproduced from Shahidi \& Zhong (2010) (doi:10.1039/B922183M) with permission of The Royal Society of Chemistry.

Fig. 2: The induction period (IP) for the formation of hydroperoxides showed by the measured mean values for peroxide values (PV). The intersection of two linear regression lines generates the point to indicate the end of the IP $\left(P V_{\mathbb{I P}}\right)$. Using the slopes of fitted regression lines, the respective oxidation rate constants $k_{1}$ and $k_{2}$ for induction and propagation can be determined.

Fig. 3: Correlation between half-lives $\left(t_{1 / 2}\right)$ of induction and propagation stages of the formation of hydroperoxides of ozone-processed shrimp.

Table 1: Oxidation rates for PV of ozone-processed shrimp

\begin{tabular}{llllll}
\hline Ozone & Treatment & \multicolumn{4}{c}{ Rate constant } \\
\cline { 2 - 6 } Exposure & Type & $\mathrm{k}_{1}\left(\mathrm{mEq} \mathrm{kg}^{-1} \mathrm{~d}^{-1}\right)$ & $\mathrm{R}^{2}$ & $\mathrm{k}_{2}\left(\mathrm{mEq} \mathrm{kg}^{-1} \mathrm{~d}^{-1}\right)$ & $\mathrm{R}^{2}$ \\
\hline $1 \mathrm{~min}$ & BIS & $0.37 \pm 0.01$ & 0.998 & $0.86 \pm 0.02$ & 0.991 \\
\multirow{3}{*}{$3 \mathrm{~min}$} & DIS & $0.64 \pm 0.02$ & 0.998 & $1.49 \pm 0.03$ & 0.976 \\
\multirow{3}{*}{$5 \mathrm{~min}$} & BIS & $0.45 \pm 0.03$ & 0.993 & $0.88 \pm 0.02$ & 0.974 \\
& DIS & $0.64 \pm 0.01$ & 0.996 & $1.42 \pm 0.02$ & 0.975 \\
& BIS & $0.39 \pm 0.04$ & 0.997 & $1.00 \pm 0.00$ & 0.973 \\
& DIS & $0.65 \pm 0.01$ & 0.997 & $1.34 \pm 0.04$ & 0.988 \\
\hline
\end{tabular}


Key: Before iced storage (BIS); During iced storage (DIS); Values presented as mean \pm standard error (of the mean) $(n=4)$

Table 2: Induction period (IP) and peroxide values at the end of the induction period $\left(\mathrm{PV}_{\mathrm{IP}}\right)$ of ozone-processed shrimp

\begin{tabular}{llll}
\hline $\begin{array}{l}\text { Ozone } \\
\text { Exposure }\end{array}$ & $\begin{array}{l}\text { Treatment } \\
\text { Regime }\end{array}$ & $\mathrm{IP}($ day $)$ & $\mathrm{PV}_{\text {IP }}(\mathrm{mEq} \mathrm{kg}$ \\
& & \\
\hline $1 \mathrm{~min}$ & BIS & $4.36 \pm 0.12$ & $2.92 \pm 0.06$ \\
& DIS & $5.92 \pm 0.12$ & $4.49 \pm 0.17$ \\
$3 \mathrm{~min}$ & BIS & $5.10 \pm 0.20$ & $3.40 \pm 0.18$ \\
& DIS & $6.14 \pm 0.09$ & $4.56 \pm 0.10$ \\
$5 \mathrm{~min}$ & BIS & $4.35 \pm 0.09$ & $2.88 \pm 0.10$ \\
& DIS & $6.12 \pm 0.04$ & $4.54 \pm 0.05$ \\
\hline
\end{tabular}

Key: Before iced storage (BIS); During iced storage (DIS); Values are given as mean \pm standard error (of the mean) $(n=4)$

Table 3: Correlation coefficients between peroxide values (PV) and induction period (IP) for the formation of hydroperoxides of ozone-processed shrimp

\begin{tabular}{|c|c|c|c|c|c|}
\hline $\begin{array}{l}\text { Ozone } \\
\text { treatment }\end{array}$ & Equation & P-value & $\begin{array}{l}\text { F- } \\
\text { change }\end{array}$ & $\begin{array}{l}\text { Correlation coefficient } \\
\text { (r) }\end{array}$ & $\begin{array}{l}R^{2} \\
(\%)\end{array}$ \\
\hline $\mathrm{BIS}$ & $-0.164+0.703$ & $<0.0001$ & 169.5 & 0.972 & 93.9 \\
\hline DIS & $-1.209+0.947$ & 0.0004 & 26.7 & 0.853 & 70.0 \\
\hline
\end{tabular}

Key: Before iced storage (BIS); During iced storage (DIS)

Table 4: Half-lives $\left(\mathrm{t}_{1 / 2}\right)$ (measured in hour $\{\mathrm{h}\}$ ) for the formation of hydroperoxides during induction and propagation stages of ozone-processed shrimp

\begin{tabular}{llll}
\hline Ozone & Treatment & \multicolumn{2}{c}{ Half-life $\left(\mathrm{t}_{12}\right)(\mathrm{h})$} \\
\cline { 4 - 4 } Exposure & Regime & Induction & Propagation \\
\hline $1 \mathrm{~min}$ & BIS & 44.9 & 19.4 \\
\multirow{3}{*}{$3 \mathrm{~min}$} & DIS & 25.9 & 11.0 \\
& BIS & 37.0 & 19.0 \\
$5 \mathrm{~min}$ & DIS & 25.9 & 11.8 \\
& BIS & 42.7 & 16.6 \\
& DIS & 25.7 & 12.2 \\
\hline
\end{tabular}

Key: Before iced storage (BIS); During iced storage (DIS) 
Initiation:

$$
\begin{gathered}
\mathrm{R}_{1} \mathrm{H} \stackrel{\text { initiator }}{\longrightarrow} \mathrm{R}_{1}^{*}+\mathrm{H}^{*} \\
\text { and/or } \quad \mathrm{O}_{2} \stackrel{\text { initiator }}{\longrightarrow} \mathrm{O}_{2}{ }^{*} \longrightarrow \mathrm{HOO} \stackrel{\mathrm{R}_{1} \mathrm{H}}{\longrightarrow} \mathrm{R}_{1}{ }^{*}+\mathrm{H}_{2} \mathrm{O}_{2}
\end{gathered}
$$

Propagation:

$\mathrm{R}_{1} \cdot \stackrel{\mathrm{O}_{2}}{\longrightarrow} \mathrm{R}_{1} \mathrm{OO}^{*} \stackrel{\mathrm{R}_{2} \mathrm{H}}{\longrightarrow} \mathrm{R}_{2} \stackrel{\mathrm{O}_{2}}{\longrightarrow} \mathrm{R}_{2} \mathrm{OO}^{*} \stackrel{\mathrm{R}_{3} \mathrm{H}}{\longrightarrow} \mathrm{R}_{3} \cdot \stackrel{\mathrm{O}_{2}}{\longrightarrow} \mathrm{R}_{3} \mathrm{OO}^{*} \stackrel{\mathrm{R}_{n} \mathrm{H}}{\rightarrow} \mathrm{R}_{\mathrm{n}} \cdot \ldots$...etc.<smiles></smiles>

$\downarrow$ heat

$\mathrm{R}_{2} \mathrm{OOH}$

oxidizing
metals

$\mathrm{R}_{3} \mathrm{OOH}$

reducing
metals

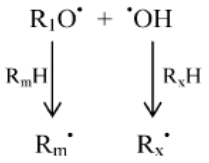

$\mathrm{R}_{2} \mathrm{OO}^{*}+\mathrm{H}^{+}$

$\mathrm{OH}+\mathrm{R}_{3} \mathrm{O}^{\circ}$

$\downarrow \mathrm{R}_{\mathrm{y}} \mathrm{H}$

$\mathrm{R}_{\mathrm{y}}$.

$\mathrm{R}_{\mathrm{z}} \mathrm{H}$
$\mathrm{R}_{\mathrm{z}} \cdot$

Termination:
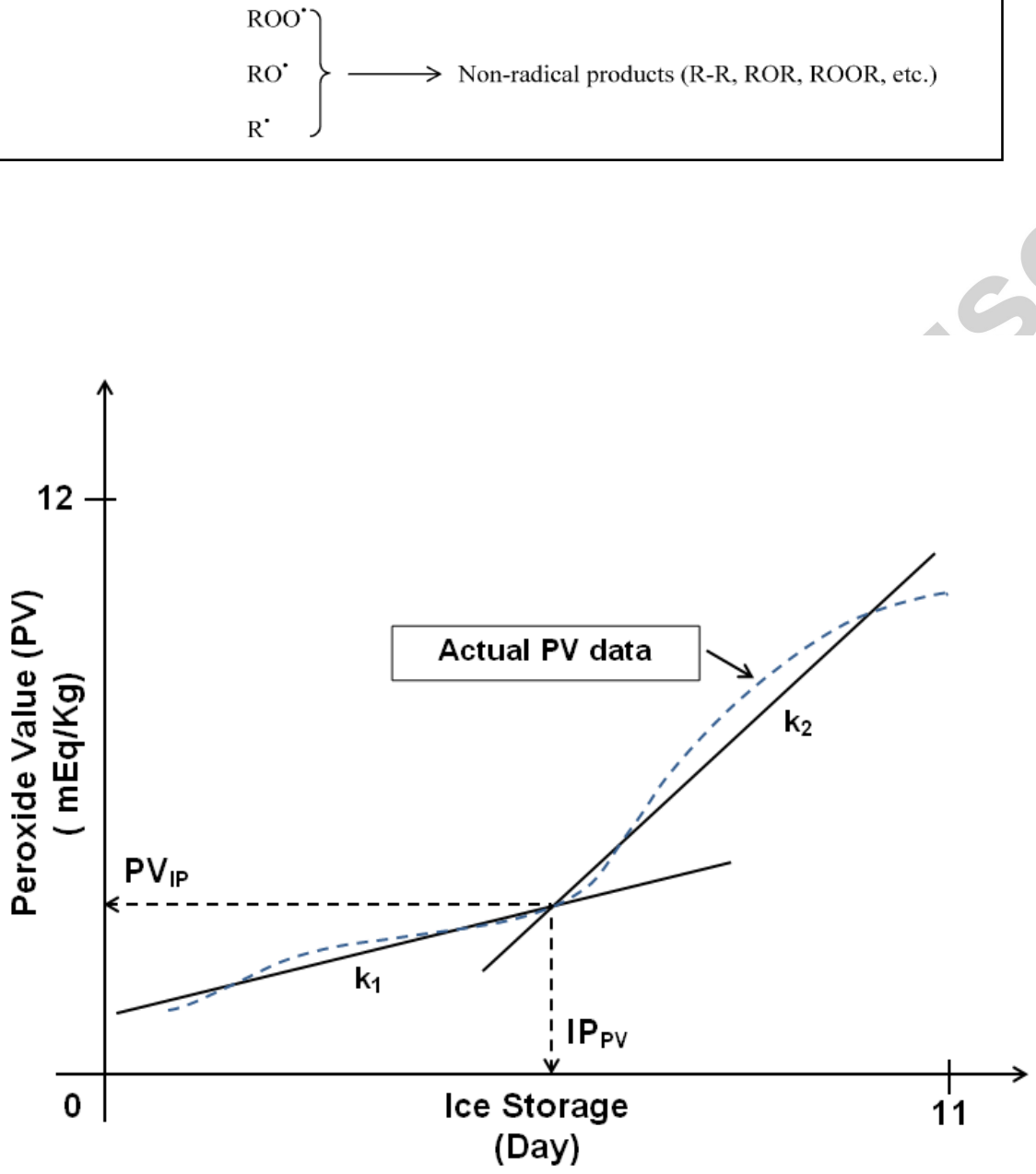


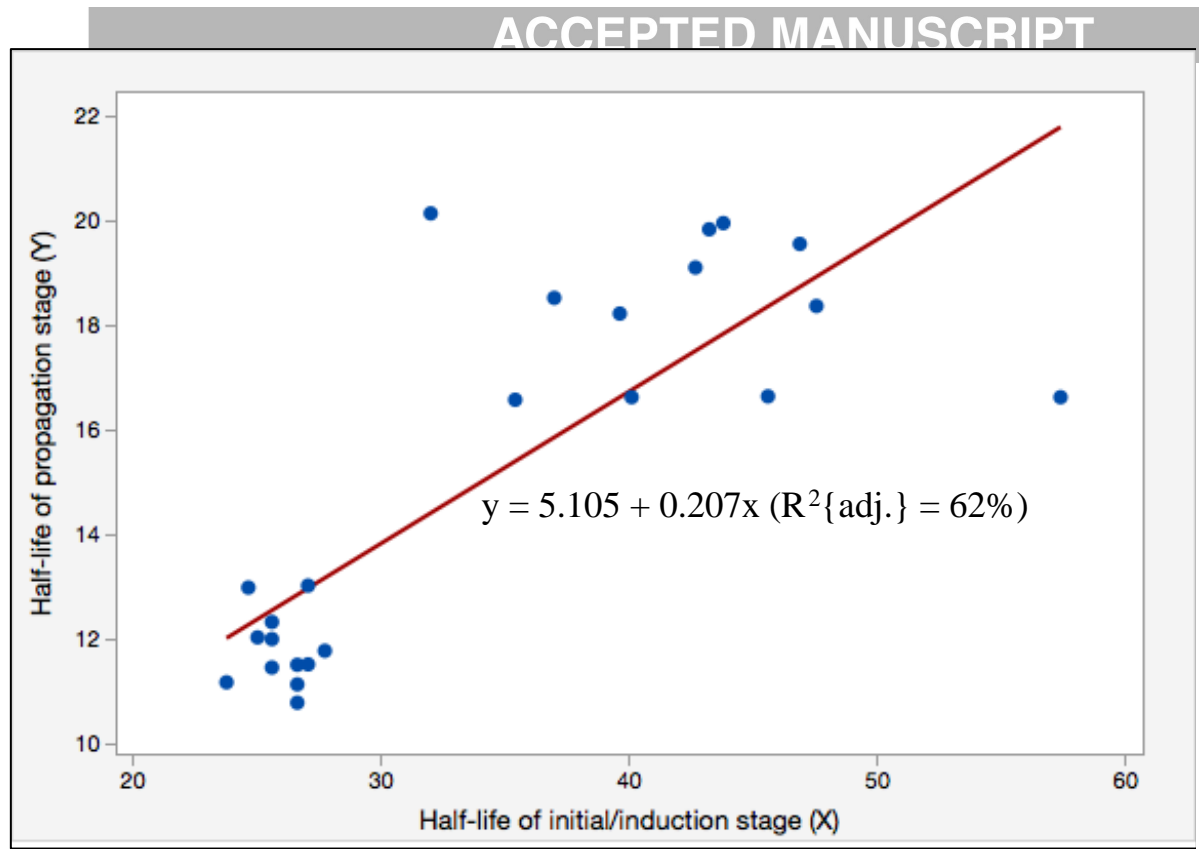

